\title{
A Socioeconomic and Productive Characterization of the Value Chain of Goldenberry (Physalis peruviana) in Ecuador
}

\author{
Moreno-Miranda Carlos ${ }^{1}$, Pilamala Araceli ${ }^{1}$, Cerda-Mejía Liliana ${ }^{1}$, \\ Cerda Mejía Víctor Rodrigo², Ortiz Jacqueline¹, Rama Daniele ${ }^{3}$
}

${ }^{1}$ Universidad Técnica de Ambato, Facultad de Ciencia e Ingeniería en Alimentos, Campus Huachi, Av de Los Chasquis, Ambato, Ecuador

${ }^{2}$ Universidad Estatal Amazónica, Departamento de Ciencias de la Tierra, Campus Central, Troncal Amazónica E45, Puyo, Ecuador

${ }^{3}$ Università Cattolica del Sacro Cuore, Alta Scuola di Management ed Economia Agro-Alimentare, Campus Cremona, Cremona, Italia

Email: *cs.moreno@uta.edu.ec

How to cite this paper: Carlos, M.-M., Araceli, P., Liliana, C.-M., Rodrigo, C.M. V., Jacqueline, O. and Daniele, R. (2018) A Socioeconomic and Productive Characterization of the Value Chain of Goldenberry (Physalis peruviana) in Ecuador. Agricultural Sciences, 9, 426-436.

https://doi.org/10.4236/as.2018.94030

Received: January 30, 2018

Accepted: April 27, 2018

Published: April 30, 2018

Copyright ( 92018 by authors and Scientific Research Publishing Inc. This work is licensed under the Creative Commons Attribution International License (CC BY 4.0).

http://creativecommons.org/licenses/by/4.0/

(c) (i) Open Access

\begin{abstract}
The fruits and vegetables sector in Ecuador despite its gradual growth in local and international markets has captured the interest of state institutions and academic centers who have focused their studies on agronomic aspects of non-traditional products without considering socioeconomic, productive and performance problems; such is the case of goldenberry value chain. To this extent, the aim of this article was to present an analysis of goldenberry value chain in Ecuador through the identification of stages, agents, flows and activities (primary and support) from the socioeconomic and productive point of view for which a systematic methodology was used involving aspects of the agroeconomic process. As a result, it was determined that goldenberry value chain in the production and postproduction stages requires the diversification of marketing channels, the implementation of refrigerated storage modules located in the supply centers, the strengthening of associative and/or cooperative structures; and the productive planning programs to provide a potential competitive advantage.
\end{abstract}

\section{Keywords}

Socioeconomic Integration, Agents, Productive, Agroeconomic Performance, Production 


\section{Introduction}

During 2005-2012 Latin American countries such as Peru, Chile, Mexico, Ecuador, Costa Rica and Colombia showed a growing trend in fruit and vegetable exports, with a moderate annual increase of $4.2 \%$ that reflects the influence of factors such as supply diversity, agricultural conditions and foreign investment [1]. Likewise, the productive chain of fruits and vegetables in Latin America is affected by losses generated throughout distinct stages and subsystems. The underutilization of production resources, caused by social, economic and political aspects, which makes it difficult to put into practicing some solutions in order to avoid commodities [1] [2].

On the other hand, Latin American countries show comparative advantages in the agricultural sector; therefore, their efforts must be consolidated as competitive advantages which incorporate efficient technology and management systems to their productive processes [3]. It is necessary to compete according to Value Chains, achieving a sustainable development in the agricultural sector, and generating a harmonious work that eases the performance of each practice, providing fluency and stability to the work of some productive agents [4] [5].

The fruits and vegetables sector in Ecuador is experiencing a gradual increase, contributing around $16 \%$ to agricultural GDP, without considering the production of potatoes and bananas [6], showing a weak integration and coordination among its agents, which makes it impossible to strategically plan future actions and the stable development of each stage of the sector [7] [8].

In this context, it has been identified that the size of farms is small, which implies increased transactional costs [9]; furthermore, the excessive diversification of plantations by producers increases the problem of marketing, because transport processes become inefficient. In the case of fruit production, the size of farms is higher but with a lesser degree of crop diversification, presenting a better coordination in the logistics of harvest, classification and other procedures demanded by national and foreign markets [10].

The production of fruits and vegetables is a viable economic alternative for average and small farmers, allowing them to simultaneously expand their supply and get opportunities of commercialization in various market niches [11]. One example is the production chain of goldenberry in the Interandean zone of Ecuador, where this study was focused on, and its performance has been improved by the expansion of modern production units from traditional models, improving its participation significantly in international markets [6]. That is why; an in-depth study related to the value chain of goldenberry is necessary, considering its social impact, growth potential, market competitiveness and other aspects of economic development.

The aim of this study was to analyze the value chain of goldenberry across the stages, agents, flows and activities (primary and support), considering socioeconomic and productive aspects, allowing the expansion of knowledge of the same 
one and contributing with the planning of competitive strategies.

This template, created in MS Word 2007, provides authors with most of the formatting.

\section{Materials and Methods}

The current study was carried out at the Interandean zone 3 of Ecuador (provinces of Cotopaxi, Tungurahua and Chimborazo) during the second semester of 2016. This zone is located geographically at $0^{\circ} 42^{\prime}$ latitude South and $80^{\circ} 00^{\prime}$ longitude West, with an average altitude of 3500 meters above sea level and an approximate extension of $59,810 \mathrm{~km}^{2}$. The average temperature of this zone ranges between $15^{\circ} \mathrm{C}$ and $25^{\circ} \mathrm{C}$. In this zone, a systemic methodology was applied which involves socioeconomic, integration, production, performance and linkage aspects among the agents, reflecting the economic process of the value chain of goldenberry, as explained below:

1) Identification of agents that make up the stages of the value chain. Information from the last census of 2013 generated by the Ministry of Agriculture, Livestock and Fishing (MAGAP) and the registration of companies involved in the value chain of goldenberry provided by the Ministry of Industries and Productivity (MIPRO), were considered. In addition, Porter's value chain scheme was applied, grouping the agents in the primary and support stages and identifying the flows of minor and major importance.

2) Sample size description. In order to determine the size of the sample at the producer level, the continuous variable that was used was the "Number of goldenberry producers registered by the MAGAP" of the provinces involved, the formula made by Sukhatme, 1957 was used. Therefore, the sample of producers of goldenberry was distributed as follows: 36 in the province of Cotopaxi, 55 in Tungurahua and 37 in Chimborazo. Whereas in the post-production stage, the information of participating companies, registered in the Ministry of Industries and productivity, was used.

3) Value chain analysis. It was carried out through the application of surveys and structured interviews considering variables of productive nature such as cultivation area, diversification of agricultural products, agronomic variety among others, while some of the socioeconomic variables used were age, level of education, main source of financing and level of associativity, finally the performance variables were gross income and profitability. The surveys were aimed to representative agents, obtaining a diagnosis of the current situation of the value chain.

4) Measuring the value chain. The dual (horizontal and vertical) structural measure existing in the value chain was established based on the information collected from the agents. The measuring scheme reported by [12] was applied, this method points the input-output structure, geographic scope, governance structure, upgrading, local institutional context and industry stakeholders as the six dimensions of the value chain analysis. 
5) Data processing method. For the analysis of the data, tools of descriptive statistical analysis and data normality test of IBM SPSS Statistics 24.0 software were used.

\section{Results and Discussion}

\subsection{Identification of Agents that Make up the Stages of the Value Chain}

The Interandean zone of Ecuador, because of its territorial characteristics, capacities and population dynamics, is considered the Agricultural collection center of the country and is an important commercial node at national level, according to the information provided by the MAGAP presented in Table 1, it was identified that for the production stage of goldenberry of Zone is counted with $0.82 \%$ of fruits and vegetables producers. At the same time, the province of Tungurahua stands out for owning the largest number of hectares for the production of goldenberry.

On the other hand, in the post-production stage, 23 companies registered in the Ministry of Industries and Productivity are identified. Between them, are Planhofa, Ecuaconservas, Terrafértil, Inphec Agroindustrial among others, of which $39.1 \%$ are purely processors, while the $60.9 \%$ processor and/or exporters. Simultaneously, it was found that $78.3 \%$ work with goldenberry, while the remaining process both goldenberry and other fruit and vegetable products and finally it was found that $39.1 \%$ of the registered companies intervene in the domestic market, while the $30.4 \%$ are exporters of various kinds of products from goldenberry and others.

With regard to distributors registered by the Ministry of Industries and Productivity, that are: Corporación La Favorita, Corporación el Rosado, Iberia Foods S.A., Gorizur among others, of which the first three are large companies that operate as retailers; while the remaining distributors are medium-sized enterprises of wholesale commercial activity.

The distributors previously mentioned have characteristics in common: they have products based on goldenberry within their business portfolio, they are not producers or processors, their suppliers are usually processors and producers,

Table 1. Total number of agricultural producers, producers of the fruits and vegetables sector, producers of goldenberry and production area of goldenberry of the provinces of Cotopaxi, Tungurahua and Chimborazo.

\begin{tabular}{ccccc}
\hline \multirow{2}{*}{ Province } & \multicolumn{3}{c}{ Total number } & Area (acres) of \\
\cline { 2 - 4 } & $\begin{array}{c}\text { Agricultural } \\
\text { producers }\end{array}$ & $\begin{array}{c}\text { Producers of the fruits and } \\
\text { vegetables sector }\end{array}$ & $\begin{array}{c}\text { Goldenberry } \\
\text { producers }\end{array}$ & $\begin{array}{c}\text { Goldenberry production } \\
\text { Cotopaxi }\end{array}$ \\
Tungurahua & 182.528 & 43.011 & 123 & Cotopaxi \\
Chimborazo & 246.132 & 37.689 & 177 & Tungurahua \\
\hline
\end{tabular}


their main method of negotiation is through direct credit, and they operate in zone 3 of the country.

The following is the scheme of goldenberry value chain in the Interandean Zone 3 of Ecuador, detailing the agents involved in it as presented in Figure 1.

Figure 1 outlines the value chain with its starting point in support activities, carried out by agents such as state and private producing companies, which provide flows of supply of seeds, machinery, fertilizers, among others property, in the same way, credit unions and the state bank are involved, who are responsible for financing the different activities along the value chain.

The next stage is the production; this is carried out by individual farmers, associations and/or agricultural cooperatives. These agents initiate high-value production flows, which are directed towards intermediaries, provincial distribution centers, district markets, private fruits and vegetables processors, entrepreneurs and artisans. In turn, these types of flows were identified in the transfer of high value-added consumer goods between transformers and retail marketing chains.

Finally, low-importance production flows were identified with the reduced participation of processors and exporters in international markets.

\subsection{Value Chain Analysis}

\subsubsection{Pre-Production}

It begins with the intervention of governmental and/or state companies that generally supply inputs as fertilizers, seeds and technical training through extensionist programs, it simultaneously has the intervention of state universities whose contribution is focused on improving productive yields, vegetable improvement and processing technology, as well as the participation of private suppliers of inputs supplying packaging material, machinery, additives, technology and advice on technical and market aspects.

\subsubsection{Production}

Socioeconomic Factor. This stage has producers between 30 and 50 years, mostly are men (56\%), their academic education is secondary (40\%) and higher (26\%). The $28 \%$ of the producers are members of associations and $39 \%$ are cooperative partners. Their source of financing in 55\% are own resources and $41 \%$ corresponds to debt.

Productive Factor. In terms of land ownership, $45 \%$ own land and $29 \%$ work in society. The $55 \%$ of the respondents have a land extension greater than 3 ha, and the cultivation area for goldenberry goes between 0.1 and 1.5 ha on average. At the same time, 56\% apply cultivation techniques to open field.

The Figure 2(a) shows that the Ecuadorian genotype is the most cultivated followed by the Colombian genotype and to a lesser extent the Kenyan. According [13], there are about 20 ecotypes (adapted genotypes) of goldenberry that differ mainly by color and size. It also mentions that in Ecuador there is an orange ecotype, adapted to the Ecuadorian agroclimatic conditions, with size of 


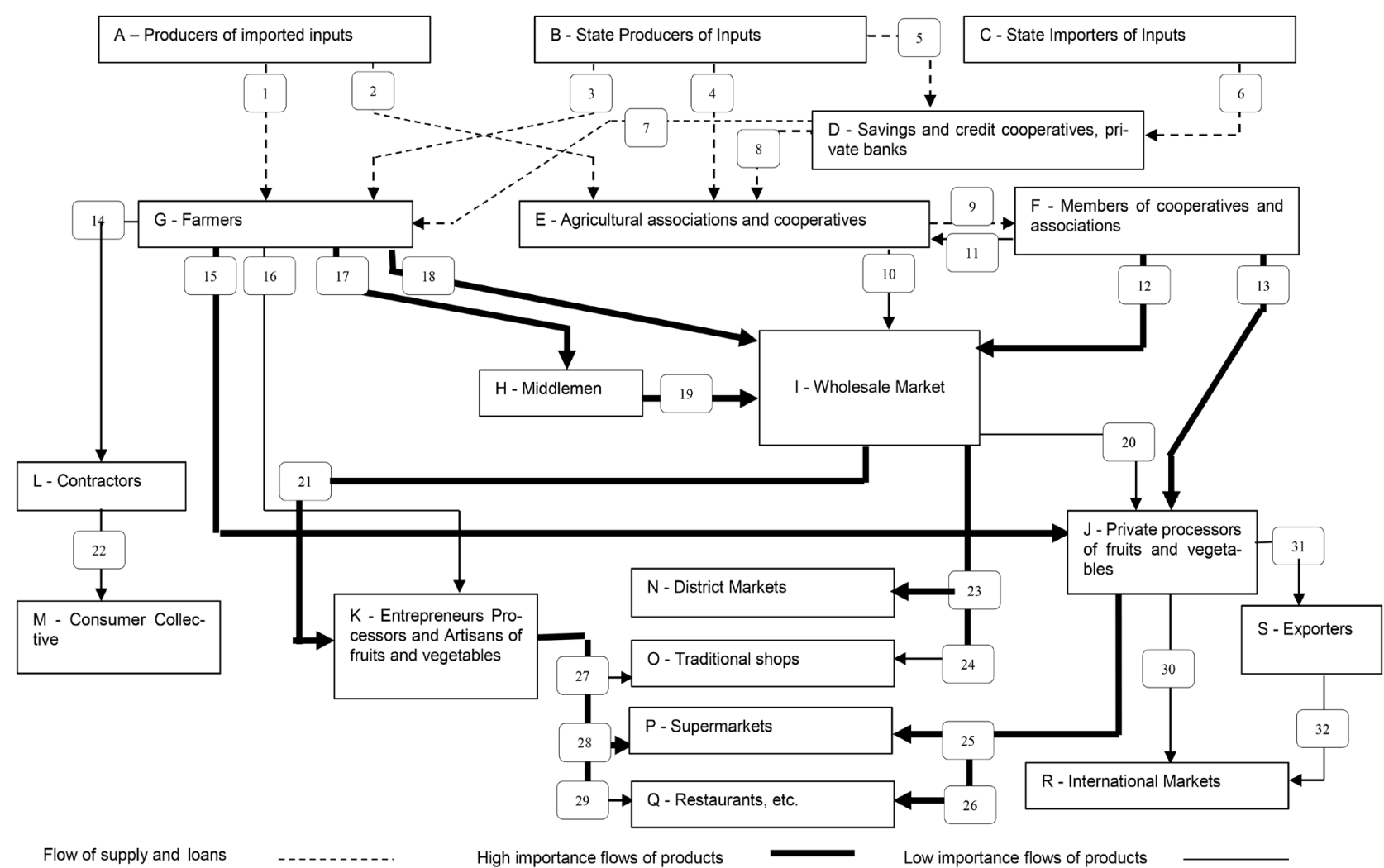

Figure 1. Agents and Flows identified in the chain.

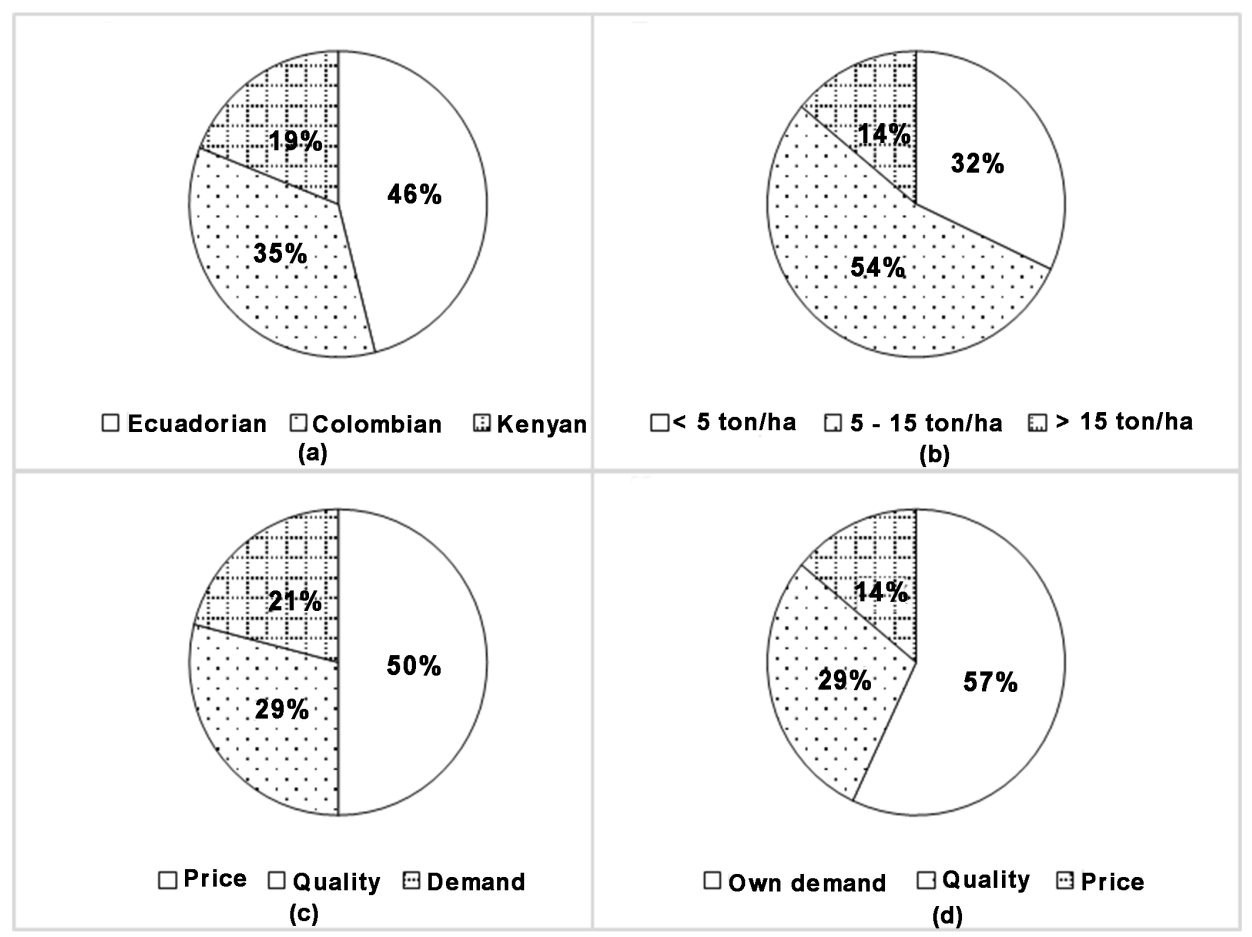

Figure 2. Economic and Productive Aspects of Value Chain. (a) Goldenberry genotypes grown in Ecuador; (b) Productive yields; (c) Decisive factors in the price the acquisition of goldenberry; (d) Decisive factors in the goldenberry to the customer. 
medium to large, and that is marketed in the national and international market and that the Colombian ecotype is not very adapted to the agroclimatic conditions of Ecuador and frequently presents phytopathological problems.

In Colombia has been the largest producer of goldenberry in the world cultivating mostly the Colombian genotype $(2 n=32)$ and to a lesser extent the Kenyan genotype $(2 \mathrm{n}=48)[14]$.

According to the results presented in Figure 2(b) and comparing with the yields [13] [14] where they mention that the yield of goldenberry in Ecuador is 13.6 ton/ha while in Colombia is around of 14.5 ton/ha, it is observed that the value chain under study presents very similar values in this variable. In addition, it is important to mention that only $33 \%$ of producers apply post-harvest techniques.

Performance Factor. The variable gross profit showed that the producers reached 10,825.92 USD/year and the net income was observed an average value of $6423.89 \mathrm{USD} / \mathrm{Ha} /$ year. It is important to mention that [15] a gross profit that goes between 8 and 10\% for the goldenberry producers in Colombia, while the MAGAP (2015) reports $27 \%$ of profit for Ecuadorian producers.

The next stage is the production; this is carried out by individual farmers, associations and/or agricultural cooperatives. These agents initiate high-value production flows, which are directed towards intermediaries, provincial distribution centers, district markets, private fruits and vegetables processors, entrepreneurs and artisans. In turn, these types of flows were identified in the transfer of high value-added consumer goods between transformers and retail marketing chains.

\subsubsection{Post-Production: Processors}

Socioeconomic Factor. Of the registered companies it was found that $43 \%$ are small companies and that includes processors and/or exporters, $14 \%$ microenterprises, $21 \%$ medium and another $21 \%$ large companies. The $64 \%$ of registered companies are members of associations and $36 \%$ are cooperative partners. On the other hand, with regard to financing $57 \%$ of them operate mostly with their own resources and debt, and $21 \%$ run it through debts and shares in the stock market.

Operative Factor. The 50\% outsource transportation service and $43 \%$ use their own and/or rented transportation. In addition, $36 \%$ of companies mention that goldenberry is their main raw material and the $93 \%$ of companies are not producers of goldenberry. Additionally, it was found that their suppliers are both producers (50\%) and middlemen (50\%). The 50\% of them have contracts with suppliers and the $79 \%$ indicate that their method of negotiation is by credit.

In Figure $2(\mathrm{c})$, it is shown that $50 \%$ of companies indicate that the market price is the decisive factor in the acquisition of goldenberry. In turn they mention that the characteristics most appreciated during the purchase are the color (36\%), the consistency (29\%), the size and shape (21\%), the physical damage and others (7\%). In addition, it was found that $57 \%$ of the companies do not carry 
out the purchase when the goldenberry is of low quality. On the other hand, it was established that $43 \%$ of the processors market goldenberry in second and fourth gamma and its delivery is made in $36 \%$ to the international market and $49 \%$ to the domestic market.

The results shown in Figure 2(d) indicate that for $57 \%$ of companies the customer's own demand is the decisive factor in the price of goldenberry. The next stage is the production; this is carried out by individual farmers, associations and/or agricultural cooperatives. These agents initiate high-value production flows, which are directed towards intermediaries, provincial distribution centers, district markets, private fruits and vegetables processors, entrepreneurs and artisans. In turn, these types of flows were identified in the transfer of high value-added consumer goods between transformers and retail marketing chains.

\subsubsection{Post-Production: Distributors}

Socioeconomic Factor. Among the distributors it was found that 50\% are SMEs and the remaining $50 \%$ are large companies. The $50 \%$ of distributors are members of associations and 100\% do not belong to cooperatives. On the other hand, with regard to financing, the $72 \%$ of them operate mostly with their own resources and debt, while $28 \%$ run it through debts and shares in the stock market.

Operative Factor. The 50\% of the companies outsource the transport and the remaining 50\% use their own transport. It was also recognized that none of the distributors are producers of goldenberry and that their purchase is directly with producers without the need of middlemen. In turn, all negotiations are by credit with a period of 20 to 40 days.

The decisive factor in the price of goldenberry to its suppliers depends exclusively on their own demand for fresh and/or processed products, while their price to the final consumer is the result of the performance of products on shelves and established profit margins.

\subsection{Dimensioning of the Value Chain}

The dimensioning found in the value chain under study shows the following schemes presented in Figure 3 and Figure 4.

In Figure 3, it is shown that the horizontal dimension describes 5 levels grouping the different agents according to the similarity of their activities, where level 1 oversees the provision of resources (support activities), level 2 focused on the agricultural production of goldenberry, level 3 with agents involved in the process of transaction of the product, level 4 directed to generate goods with added value, and level 5 as responsible for the transfer of goods to the final consumer.

With regard to the vertical dimension described in Figure 4, it is shown that the value chain under study describes levels $1,3,4$ and 5 as narrow structures, i.e. levels that have a low level of fragmentation (relatively few agents), while level 2 presents a large structure by the high number of agents involved. 


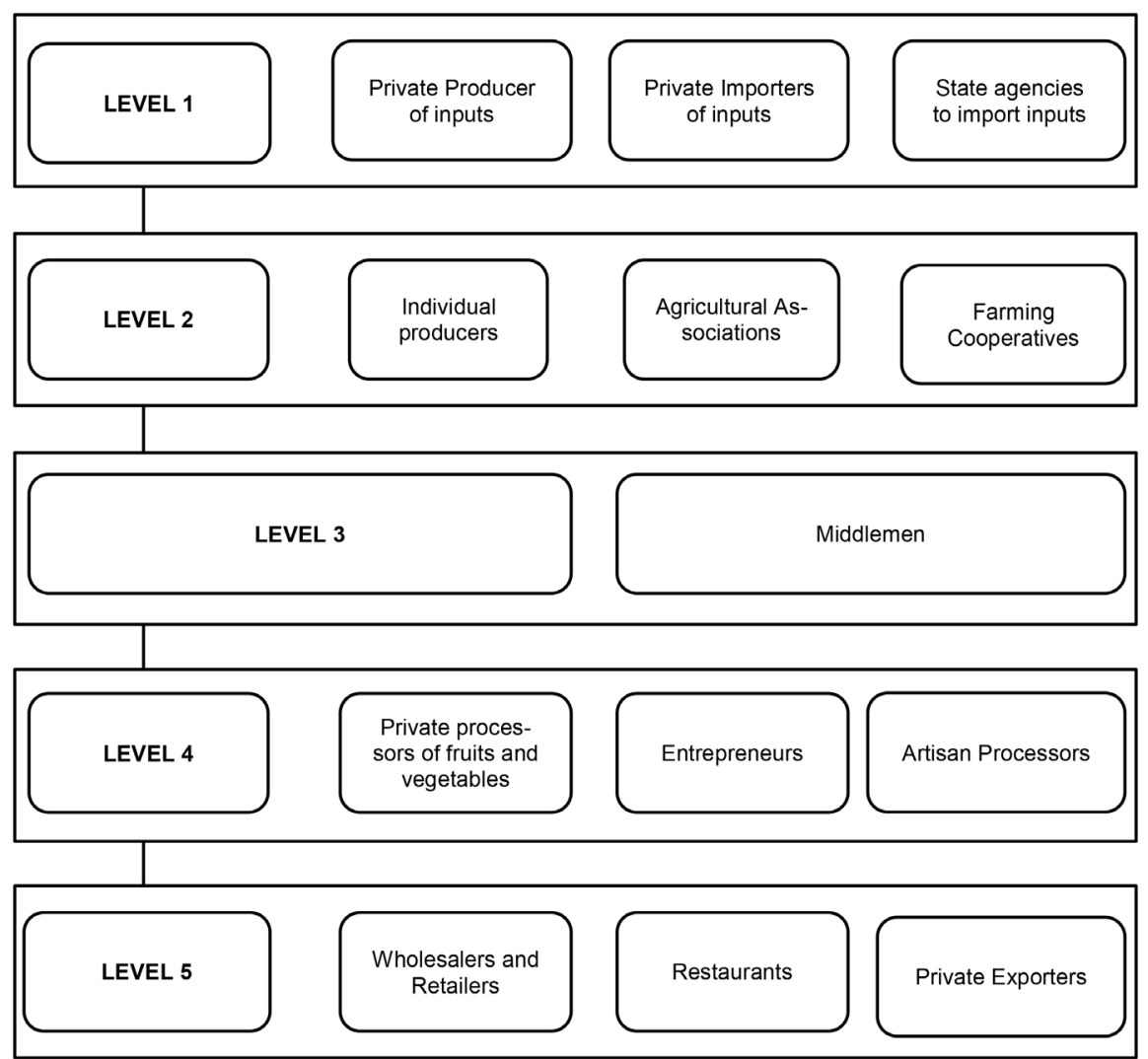

Figure 3. Horizontal dimensions of goldenberry value chain.
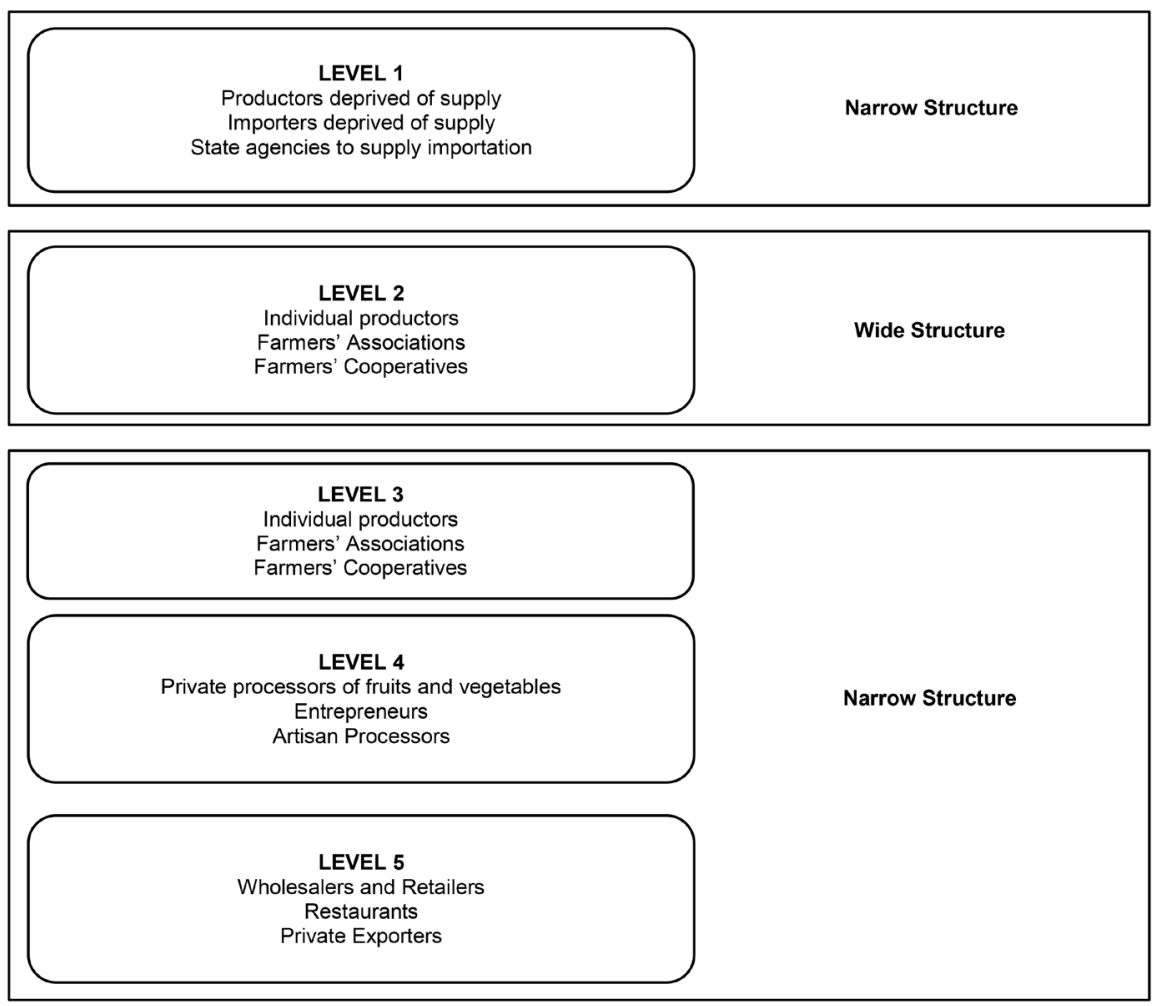

Figure 4. Vertical dimensions of the goldenberry value chain. 
The governance process of a value chain generated by the dimensioning allows understanding the dynamics between stages and agents. The fruit value chain in Colombia presents a fragmented stage of production, but with a high participation of artisans and small businesses in the processing link (28\%). The value chain of goldenberry in the Interandean zone of Ecuador presents a relatively fragmented stage of production in comparison with the other stages (processing, distribution) where the intervention of agents is reduced, concentrating there the market power of this product [16].

\section{Conclusions}

In the pre-production stage, where public and private institutions are involved, the main support activities are carried out and where the flows of tangible and non-tangible resources necessary for the performance of the value chain are created, also it does not present difficulties that represent a slowed growth in the different primary activities and flows of products of high and low importance.

On the other hand, the production stage has producers with favorable demographic characteristics (age and location), but in the same way it presents aspects that require attention, for example, the strengthening of associative structures and cooperatives, with a business vision that promotes the chain, improving its participation in national and international markets. An additional aspect is the productive factors, these require a re-engineering, that results in the significant increase of the area of cultivation of goldenberry, improvement in the techniques of production and yields as well as a broad application of post-harvest practices.

The goldenberry value chain in the Interandean zone presents a post-production stage that clearly defines the power of processors and distributors. Small businesses are mostly involved in value-added activities and present a very important percentage of membership in associations. A clear example is the presence of the ANFAB (National Association of Food and Beverage Manufacturers), an entity that brings together more than 2000 companies and has established itself as a strategic partner in the country's food and agriculture sector.

Moreover, the distribution companies also present an important sense of associativity, but they are characterized by the business model with which they operate, for example, participating in the stock market, implementing methods of negotiation under credit that generate positive cash flows, and establishing decisive factors in prices towards suppliers and consumers.

Finally, the analysis of the measuring indicates that the value chain under study requires diversification of marketing channels is able to expand markets, the implementation of refrigerated storage modules located in supply centers, and productive planning programs that reduce crop dispersion, oversupply and improve the allocation of support resources, as well as the governance of it.

\section{References}

[1] OCDE/CEPAL/CAF (2015) Economic Perspectives of Latin America 2016. Towards 
a New Partnership with China.

[2] FAO (2012) Loss and Waste of Food in the World-Scope, Causes and Prevention. FAO, Quebec City.

[3] Orjuela Castro, J.A., Castañeda Calderón, C.A. and Calderon, M.E. (2008) Analysis of the Value Chain in the Productive Structures of Goldenberry and Tamarillo in the Province of Sumapaz and the Capital District. Engineering, 13, 4-12.

[4] Miranda Lasprilla, D. (2011) Current State of Colombian Fruticulture and Perspectives for Its Development. Rev. Bras. Frutic, , 199-205.

[5] Scott, G.J. (2013) Adding Values to Value Chains. Revista de Administração de Empresas, 54, 67-79. https://doi.org/10.1590/S0034-759020140107

[6] MAGAP (2016) The Ecuadorian Agricultural Policy. MAGAP.

[7] Hinojosa Rojas, M.J. and Ipiales Pupiales, M.V. (2015) Strategies for Strengthening the Productive Chain of the Goldenberry as a Contribution to the Development of the Rural Areas of the Province of Imbabura. Central University of Ecuador, Quito.

[8] Mosquera, V.B., Alwang, J., Andrango, G., Domínguez, J., Escudero, L. and Martínez, A. (2017) Value-Chain Upgrading for Ecuador's Blackberry Producers and Impacts on Prices Received. Minist. Agric. y Ganad., 1-42.

[9] Blandon, J., Henson, S. and Cranfield, J. (2008) Small-Scale Farmer Participation in New Afri-Food Supply Chains: Case of the Supermarket Supply Chain for Fruit and Vegetables in Honduras. The International Journal of Developmental, 96, 971-984.

[10] IFAD (2011) IFAD Annual Report 2011.

[11] Dunn, J., Harper, J. and Lynn, K. (2015) Commercialization of Fruits and Vegetables for Small-Scale and Part-Time Producers. Agric. Altern., No. 1, 1-6.

[12] Gereffi, G. and Fernandez-Stark, K. (2016) Global Value Chain Analysis: A Primer.

[13] Altamirano, M. (2010) Study of Goldenberry (Physalis peruviana L.) Productive Chain in the Northern Highland Region of Ecuador. Universidad San Francisco de Quito, Quito.

[14] Fischer, G., Almanza-Merchán, P.J. and Miranda, D. (2014) Importance and Cultivation of the Goldenberry (Physalis peruviana L.) 1. Revista Brasileira de Fruticultura, 36, 1-15. https://doi.org/10.1590/0100-2945-441/13

[15] Rubiano Pinto, A.J. (2013) Manual for the Goldenberry Exports from Colombia to South Korea by Air. La Salle University, Philadelphia.

[16] Tobasura, A.I. and Ospina, P.C. (2010) The Governance Process of the Blackberry Chain. A Case Study in the Department of Caldas (Colombia). Spatial Dynamics in Agri-Food Systems. Implications for Sustainability and Consumer Welfare, , 1-13. 